\title{
Experimental Study on the Impact Fatigue Behavior of GFRP Mesh Reinforced ECC for Runway Pavement Application
}

\author{
Yang Pan and Chao $\mathrm{Wu}^{*}$ \\ School of Transportation Science and Engineering, Beihang University, 37 Xueyuan Road, Beijing 100191, China
}

\begin{abstract}
Concrete pavement is easy to crack and generate the chunks, which may destroy the engine of the airplane and maintenance cost is very expensive. Engineered cementitious composites (ECC) is ductile with microcracks, but its strength is low. Glass Fiber Reinforced Polymer (GFRP) mesh imbedded in ECC could improve the strength. This paper investigates the impact fatigue behaviour of ECC and GFRP mesh reinforced ECC under 5 different impact pressures (1.61 $\mathrm{MPa}, 1.88 \mathrm{MPa}, 2.10 \mathrm{MPa}, 2.41 \mathrm{MPa}$ and 3.60 $\mathrm{MPa})$, the concrete specimens were also tested for comparison. The pulse velocity through the specimens was also tested to analyse the damage of the specimens. The experimental results show that GFRP mesh reinforced ECC has improved impact fatigue behaviour than ECC specimens. The concrete specimens were all broken after a few impacts, but the GFRP mesh reinforced ECC specimens were all not broken after impacted for 30000 times. The impact fatigue behaviour of ECC reinforced with two layers of GFRP mesh with a grid dimension of $10 \mathrm{~mm}$ was the best, which is a desirable pavement composite comparing to the ordinary concrete and ECC without reinforcements.
\end{abstract}

Key words. Impact fatigue behavior, Engineered cementitious composites (ECC), Glass Fiber Reinforced Polymer (GFRP) mesh, Runway pavement

\section{Introduction}

Concrete is an important runway pavement material, but it is easy to crack and generate the chunks [1-2]. Engineered cementitious composites (ECC) is ductile with a strain capacity up to $7 \%$ [3]. However, the tensile strength of the ECC is low [3-4]. Glass Fiber Reinforced Polymer (GFRP) mesh has been used as the reinforcement embedded in the concrete to improve the strength of the concrete in recent years [5]. Impact fatigue behavior is important for the runway pavement, because the runway pavement has to carry the cyclic impact pressure in the design life of 30 years [6]. However, there is no research about the impact fatigue behavior of the runway pavement [7-9]. This paper presents an experimental program to characterize the impact fatigue behavior of ECC with/without GFRP mesh reinforcements with different grid sizes. For comparison purpose, the ordinary concrete specimens with the same compressive strength as the ECC specimens were also investigated. The pulse velocity through the specimens was also tested to analyse the effect of the impact times and the impact pressure on the damage of the specimens.

\section{Experimental program}

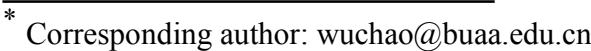

\subsection{Materials and mix proportions}

ECC specimens were mixed with the raw materials including ordinary Portland cement, fly ash, fine aggregate (F-75 silica sand), water, olycarboxylate-based high range water reducing admixture (HRWRA) and the $12 \mathrm{~mm}$ long Poly-Vinyl Alcohol (PVA) fibers (Kuraray Trading Co., LTD). The mixture of the ECC specimens is shown in Table 1 . The concrete specimens (C) with similar compressive strength to ECC were also prepared. The mix proportion of $\mathrm{C}$ is presented in Table 2. Two kind of Glass Fiber Reinforced Polymer (GFRP) mesh were used as reinforcements of the ECC specimens. The properties of the GFRP mesh provided by the manufacturer is shown in Table 3. The photos of GFRP mesh are shown in Fig. 1.

Table 1. The mixture of the ECC specimens

\begin{tabular}{|c|c|c|c|c|c|}
\hline $\begin{array}{c}\text { Water } \\
(\mathbf{W}) \\
\left(\mathbf{k g} / \mathbf{m}^{\mathbf{3}}\right)\end{array}$ & $\begin{array}{c}\text { Cement } \\
(\mathbf{C}) \\
\left(\mathbf{k g} / \mathbf{m}^{\mathbf{3}}\right)\end{array}$ & $\begin{array}{c}\text { Fly ash } \\
(\mathbf{F A}) \\
\left(\mathbf{k g} / \mathbf{m}^{\mathbf{3}}\right)\end{array}$ & $\begin{array}{c}\text { Silica } \\
\mathbf{s a n d} \\
\left(\mathbf{k g} / \mathbf{m}^{\mathbf{3}}\right)\end{array}$ & $\begin{array}{c}\text { PVA fiber } \\
\left(\mathbf{k g} / \mathbf{m}^{\mathbf{3}}\right)\end{array}$ & $\begin{array}{c}\text { HRWRA } \\
\mathbf{~ k g / \mathbf { m } ^ { 3 }}\end{array}$ \\
\hline 449 & 300 & 950 & 500 & 26 & 3.3 \\
\hline
\end{tabular}


Table 2. The mixture of the concrete specimens $\left(\mathrm{kg} / \mathrm{m}^{3}\right)$

\begin{tabular}{|c|c|c|c|}
\hline Cement & Sand & Stone & Water \\
\hline 490 & 590 & 1100 & 220 \\
\hline
\end{tabular}

Table 3. The properties of the GFRP mesh

\begin{tabular}{|c|c|c|c|c|}
\hline \multirow[t]{2}{*}{ ID } & \multirow{2}{*}{$\begin{array}{c}\text { Grid } \\
\text { dimensio } \\
\mathbf{n} \\
(\mathbf{m m} \times \\
\mathbf{m m})\end{array}$} & \multirow{2}{*}{ 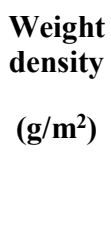 } & \multicolumn{2}{|c|}{$\begin{array}{c}\text { Tensile strength } \\
\text { (N/25mm) }\end{array}$} \\
\hline & & & $\begin{array}{c}\text { Transversa } \\
1\end{array}$ & $\begin{array}{c}\text { Longitudina } \\
\text { l }\end{array}$ \\
\hline M-10 & $10 \times 10$ & 125 & $\geqslant 900$ & $\geqslant 900$ \\
\hline M-6 & $6 \times 6$ & 300 & $\geqslant 2000$ & $\geqslant 2000$ \\
\hline
\end{tabular}

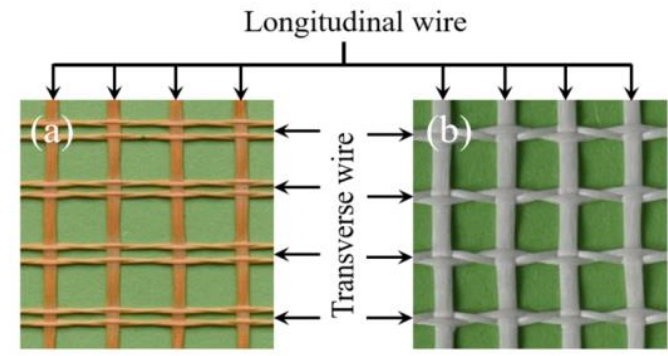

Fig. 1. GFRP mesh (a) M-10, (b) M-6

\subsection{Sample preparation}

GFRP mesh (M-10, M-6) were cut into the size of 200 $\mathrm{mm} \times 200 \mathrm{~mm}$. For ECC specimens reinforced with GFRP mesh, firstly, the first layer of fresh ECC was pored in the mold to the thickness of $10 \mathrm{~mm}$. Then the first layer of mesh was put on top of the first layer ECC. Then another $10 \mathrm{~mm}$ thick layer of fresh ECC was pored on top of the mesh. After that, the second layer of mesh was applied followed by the previous procedure by poring the last $10 \mathrm{~mm}$ thick fresh ECC layer. All the specimens were demolded after curing for 1 day. Then all specimens were cured for another 27 days in air under the temperature of $20 \pm 3{ }^{\circ} \mathrm{C}$, and a humidity of $30 \% \pm$ $5 \%$ RH. $200 \mathrm{~mm} \times 200 \mathrm{~mm} \times 30 \mathrm{~mm}$ slabs were prepared for the characterization of the impact fatigue behavior of ECC (E), the concrete (C) and GFRP mesh reinforced ECC specimens (EM-10, EM-6).

\subsection{Experimental testing}

The numerical controlled cyclic impact testing machine [10] is shown in Fig. 2. This machine was modified based on JDS-1 digital controlled electric soil compactor.
A round industrial rubber (Hardness: $50^{\circ}$ ) was glued on the head of the impact hammer to simulate the tyre of the aircraft. The diameter of the circular hammer head was $50 \mathrm{~mm}$, and the thickness of the rubber was $5 \mathrm{~mm}$. The impact frequency was 23 times/min. A wooden case was fixed on the steel frame on the ground. The concrete base was put at the bottom of the wooden case. The specimen was put on top of the concrete base, and the gap between the specimen and the wooden case was 3 $\mathrm{mm}$. 5 different impact pressures were chosen: $1.61 \mathrm{MPa}$, 1.88 MPa, 2.10 MPa, 2.41 MPa, 3.60 MPa. 4 kinds of specimens: E, C, EM-6, EM-10 were all tested under the 5 impact pressures. The total number of the tested specimens was 20 . The first crack was observed by eyes [9]. And the ultimate failure of the specimen was determined when the crack penetrated the entire depth of the specimen [9].
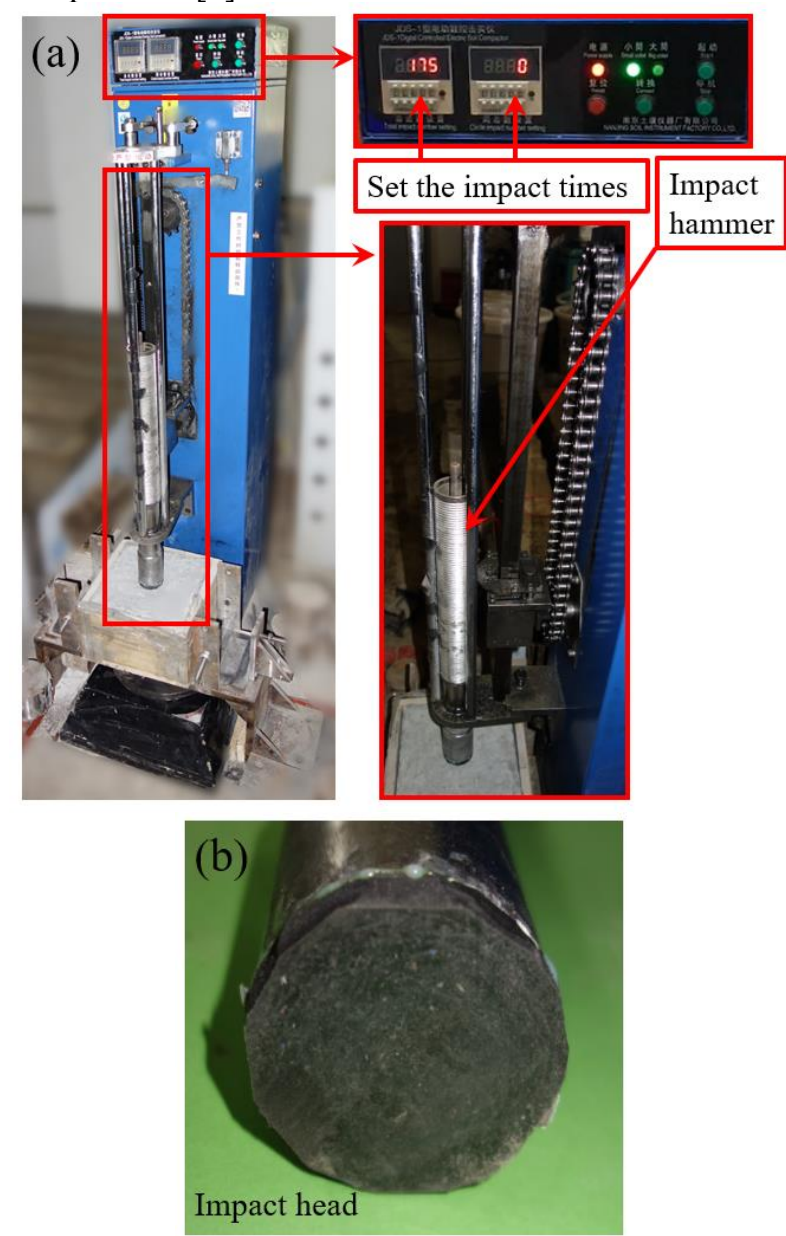

(c)

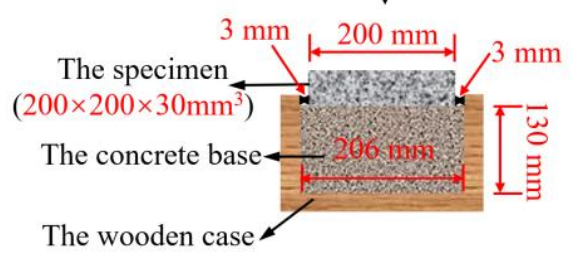

Fig. 2. The set-up of the cyclic impact test (a) The numerical controlled cyclic impact testing machine (b) The impact head (c) The concrete base and the wooden case 
To characterize the cumulative damage to the runway pavement caused by the cyclic impact pressure, an ultrasonic testing method [11] was also used to analyse the damage of the specimens after being impacted. The set-up of the ultrasonic test is shown in Fig. 3.

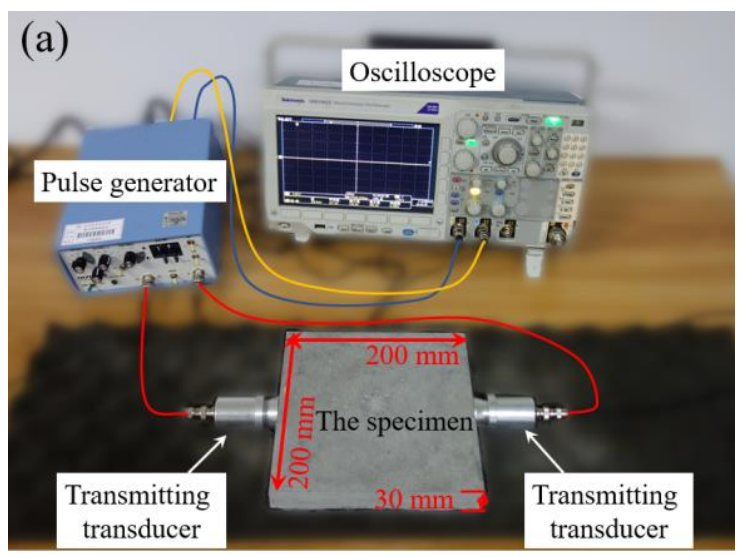

(b)

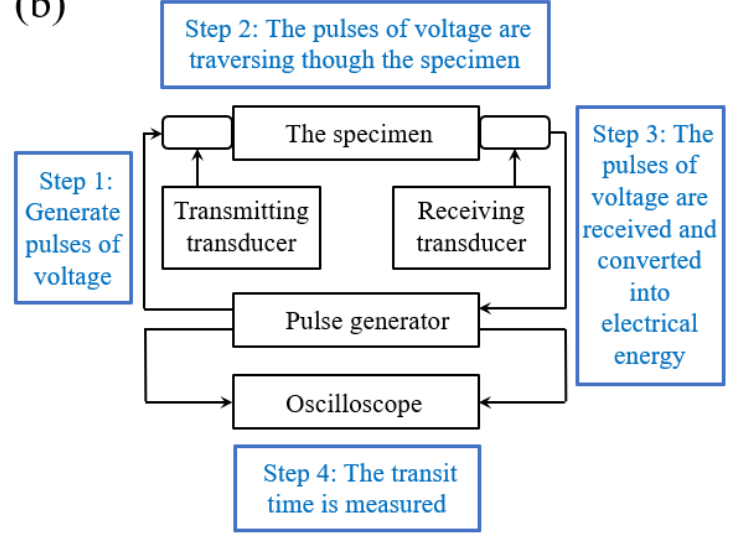

Fig. 3. The set-up and the brief schematic diagram of the ultrasonic test (a) The set-up of the ultrasonic test (b) The brief schematic diagram of the ultrasonic test

The set-up consists of a pulse generator (model 5577PR from Olympus Co., Ltd.), an oscilloscope (model DPO2014 from Tektronix, Inc.), and two acoustic sensors (model P28F-50K from Shantou Institute of Ultrasonic Instruments Co., Ltd.). The pulse generator and one sensor used as transmitting transducer could generate voltage pulses. After the pulses of voltage traversing through the specimen, the pulses are received by the other sensor used as receiving transducer and converted into electric energy. The transit time $(\mathrm{T})$ is measured electronically. The pulse velocity $\mathrm{V}$ could be calculated by dividing the distance $\mathrm{L}$ (which is equal to the length of specimens: $200 \mathrm{~mm}$ ) between the transmitting and receiving transducers, by the transit time $\mathrm{T}$. The more damages the specimen have, the lower the pulse velocity would be.

\section{Experimental results and discussions}

The impact times of the first crack and the full-depth crack of the specimens are shown in Fig. 4. It can be seen in Fig. 4 that, the impact times of the first crack of EM-10 specimens were about 2 times of the ones of the
ECC specimens and about 1.3 times of the ones of EM-6 specimens. EM-10 specimens could bear more impact times until the first crack appeared.
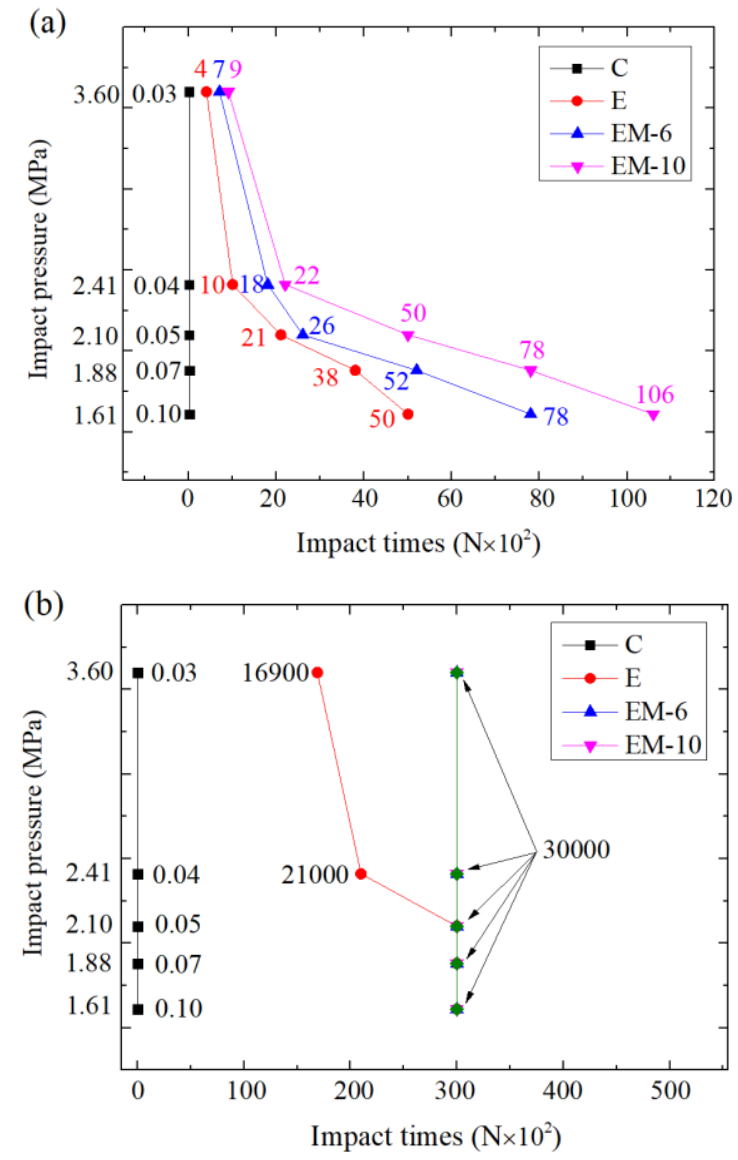

Fig. 4. Impact times of C, E, EM-6 and EM-10 under different impact pressures (a) The first crack (b) the full-depth crack

The concrete specimens were broken once the first crack appeared as shown in Fig. 5. The impact times of the full-depth of ECC specimens were 21000 and 16900 under the impact pressure of $2.41 \mathrm{MPa}$ and $3.60 \mathrm{MPa}$, respectively. Other specimens did not have the full-depth crack after being impacted for 30000 times. The photos of the bottom of all specimens is shown in Fig. 5, white lines were also added to indicate the cracks for comparison. A red circle was also drawn on the photos of Fig. 5. The diameter of the red circle was $150 \mathrm{~mm}$.

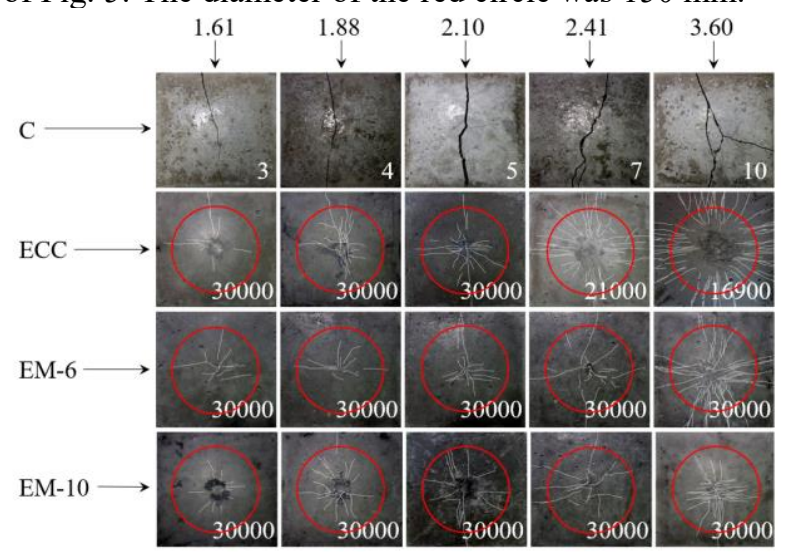

Fig. 5. The photos of the specimens after the cyclic impact test 
Compared with the concrete, which were broken with the macrocracks, the ECC specimens and GFRP mesh reinforced ECC specimens all generated microcracks instead of the macrocracks under the cyclic impact pressure. As the impact pressure increased, the number of the cracks increased. The number of the cracks of the ECC specimens was much more than the one of EM-6 and EM-10 specimens under the same impact pressure. The numbers of the cracks of EM-6 and EM-10 under the same impact pressure (1.61 $\mathrm{MPa}, 1.88 \mathrm{MPa}, 2.10$ $\mathrm{MPa}$ and $2.41 \mathrm{MPa}$ ) were close, but there were more long cracks of EM-6 (under the impact pressures of 1.61 $\mathrm{MPa}, 1.88 \mathrm{MPa}, 2.10 \mathrm{MPa}$ ) which extended to the edge of the specimens.

The pulse velocity $(\mathrm{V})$ through EM-10 was recorded every $50 \times 10^{2}$ impacts under 5 different impact pressures. The pulse velocity of EM-10 before the impact test was also tested to compare. The results are shown in Fig. 6.

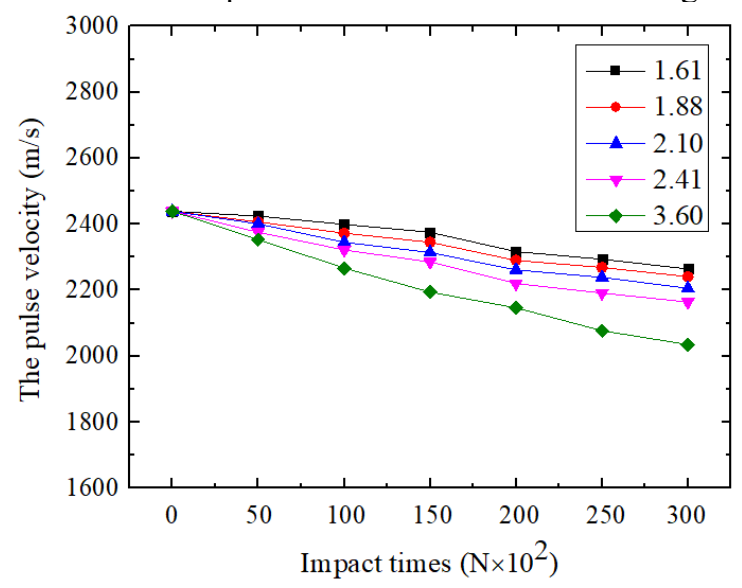

Fig. 6. The pulse velocity through EM-10

It can be seen in Fig. 6, as the impact times increased, the pulse velocity of EM-10 decreased under the same impact pressure. As the impact pressure increased, the pulse velocity decreased after the same impact times. The specimen with more cracks has smaller pulse velocity. This indicates the pulse velocity could be used to characterize the damages in ECC specimens.

\section{Conclusions}

This paper investigated the impact fatigue behaviour of the ECC specimens and GRRP mesh reinforced ECC specimens. Ordinary concrete specimens were also tested for comparison purpose. Based on the research of this study, the following conclusions could be drawn:

(1) The concrete specimens were broken with macrocracks under the impact pressure. The ECC, and the GFRP mesh reinforced ECC specimens generated microcracks instead of the macrocracks under the cyclic impact pressure. The ECC specimens were broken under the impact pressures of $2.41 \mathrm{MPa}, 3.60 \mathrm{MPa}$ after being impacted for 21000, 16900 times, respectively. The other ECC specimens and all the GFRP mesh reinforced ECC specimens were not broken after impacted for 30000 times. The damages of EM-10 was less than the damages of $\mathrm{E}$ and EM-6 under the same impact pressure.
(2) Under different impact pressures, the damages of the EM-10 specimens was different. More cracks could be observed, when the impact pressure increased.

(3) EM-10 specimens could be used as the runway pavement, because it has the best impact fatigue behaviour. The pulse velocity of EM-10 decreased, as the impact times increased or the impact pressures increased. The pulse velocity could be used to characterize the damages in ECC specimens. More importantly, there is no concrete debris generated which reduces the hazard to the road users. Therefore, the experimental results in this paper prove that EM-10 is a desirable pavement material comparing to the ordinary concrete in terms of impact fatigue behaviour.

Acknowledgement. The authors gratefully acknowledge the financial support provided by the National Science Foundation of China (51608020). This work was also funded by the Thousand Talents Plan (Young Professionals) in China.

\section{References}

1. Ahmed I, Rahman M H, Seraj S M. Performance of Plain Concrete Runway Pavement[J]. Journal of Performance of Constructed Facilities, 1998, 12(3):145-152.

2. Karakouzian M. Airfield Pavements : Challenges and New Technologies[C]. Airfield Pavements Specialty Conference, Las Vegas, Nevada, United States, September 21-24, 2003.

3. Li VC. Tailoring ECC for special attributes: A review $[\mathrm{J}]$. International Journal of Concrete Structures and Materials, 2012, 6(3):135-144.

4. Li VC. Bendable concrete[J]. Innovation in Construction, 2016, 11-15.

5. Saafi M. Design and Fabrication of FRP Grids for Aerospace and Civil Engineering Applications[J]. Journal of Aerospace Engineering, 2000, 13(4):144149.

6. MH/T5004-2010, Speclflcations for Airport Cement Concrete Pavement Design[S], Beijing, China, 2010.

7. Ranade R, Li VC, Heard WF, Williams BA. Impact resistance of high strength-high ductility concrete[J]. Cement \& Concrete Research. 2017, 98:24-35.

8. Wu J, Liu X, Zhang C. Experimental study on multilayer composite pavement system under drop weight impacts (C). Proceedings of the 24th Australian Conference on the Mechanics of Structures and Materials, Perth, Australia, December 6-9, 2016.

9. Ramakrishna G, Sundararajan T. Impact strength of a few natural fibre reinforced cement mortar slabs: a comparative study[J]. Cement \& Concrete Composites, 2005, 27(5):547-553.

10. Zhang J S, Zhang $\mathrm{W} \mathrm{M,} \mathrm{A} \mathrm{new} \mathrm{equipment} \mathrm{and} \mathrm{the}$ test method for the impact fatigue test of the concrete, CN201711235189.2, China, 2017.

11. ASTM C597-02. Standard test method for pulse velocity through concrete. United States, 2002. 